\title{
Cluster multispacecraft observations at the high-latitude duskside magnetopause: implications for continuous and component magnetic reconnection
}

\author{
A. Retinò ${ }^{1}$, M. B. Bavassano Cattaneo ${ }^{2}$, M. F. Marcucci ${ }^{2}$, A. Vaivads ${ }^{1}$, M. André ${ }^{1}$, Y. Khotyaintsev ${ }^{1}$, T. Phan ${ }^{3}$, \\ G. Pallocchia ${ }^{2}$, H. Rème ${ }^{4}$, E. Möbius ${ }^{5}$, B. Klecker ${ }^{6}$, C. W. Carlson ${ }^{3}$, M. McCarthy ${ }^{7}$, A. Korth ${ }^{8}$, R. Lundin ${ }^{9}$, and \\ A. Balogh ${ }^{10}$ \\ ${ }^{1}$ Swedish Institute of Space Physics, Uppsala, Sweden \\ ${ }^{2}$ IFSI-CNR, Roma, Italy \\ ${ }^{3}$ University of California, Berkeley, USA \\ ${ }^{4}$ CESR, Toulouse, France \\ ${ }^{5}$ University of New Hampshire, Durham, USA \\ ${ }^{6}$ MPE, Garching, Germany \\ ${ }^{7}$ University of Washington, Seattle, USA \\ ${ }^{8}$ MPS, Lindau, Germany \\ ${ }^{9}$ Swedish Institute of Space Physics, Kiruna, Sweden \\ ${ }^{10}$ Imperial College, London, UK
}

Received: 28 May 2004 - Revised: 15 October 2004 - Accepted: 21 October 2004 - Published: 28 February 2005

\begin{abstract}
We report multispacecraft Cluster observations of magnetic reconnection at the high-latitude magnetopause/magnetospheric boundary layer (MP/BL) under mainly northward interplanetary magnetic field (IMF) conditions. The event we study is on 3 December 2001 when the Cluster spacecraft were skimming the high-latitude duskside MP/BL during a period of about four hours. The orbit and configuration of the spacecraft were such that at least one satellite was present in the MP/BL during most of that period. We present the evidence of reconnection in the form of tangential stress balance between the magnetosheath and the MP/BL (Walén test) and in several cases in the form of transmitted magnetosheath ions in the MP/BL and incident/reflected magnetosheath ions in the magnetosheath boundary layer (MSBL) . The observations are consistent with magnetic reconnection occurring tailward of the cusp and going on continuously for a period of about four hours. The observed directions of the reconnection flows are consistent with the IMF orientation, thus indicating that reconnection is globally controlled by the IMF. Observations of a few flow reversals suggest passages of the spacecraft close to the X-line. The observation of low magnetic shear across the magnetopause during a flow reversal is consistent with component merging at least in one case. The observation of reconnection flows on the duskside magnetopause irrespective of the change in the sign of the IMF $B_{Y}$ also suggests a
\end{abstract}

Correspondence to: A. Retinò

(alessandro.retino@irfu.se) better agreement with the component merging model, though antiparallel merging cannot be excluded because the distance from the $\mathrm{X}$-line is not known.

Key words. Magnetospheric physics (magnetopause, cusp and boundary layers; solar wind-magnetosphere interactions) - Space plasma physics (magnetic reconnection)

\section{Introduction}

Magnetic reconnection on the Earth's magnetopause is considered to be the most efficient mechanism to transfer mass, momentum and energy from the solar wind to the Earth's magnetosphere (Cowley, 1984). Evidence of magnetic reconnection can be fluid and/or kinetic. The fluid (MHD) evidence is the tangential stress balance across the magnetopause/magnetospheric boundary layer (MP/BL), the socalled Walén test (Hudson, 1970; Paschmann et al., 1979, 1986; Sonnerup et al., 1981). The kinetic evidence is in the form of observations of particle distribution functions on reconnected field lines, such as transmitted magnetosheath ions in the MP/BL and reflected magnetosheath ions in the magnetosheath boundary layer (MSBL)(Cowley, 1982, 1995; Fuselier, 1995). The fluid and kinetic evidence gives complementary information about the occurrence of reconnection and are mutually consistent (Gosling et al., 1990; Bauer et al., 2001; Phan et al., 2001). 
At high-latitudes reconnection occurs tailward of the cusp for northward IMF. Evidence of high-latitude reconnection consists of accelerated sunward ion flows in the lobes and of D-shaped distribution functions for the ions transmitted across the magnetopause, as established by in-situ observations (Gosling et al., 1991, 1996; Kessel et al., 1996; Safrankova et al., 1998; Avanov et al., 2001; Phan et al., 2003). In this study we find similar evidence of magnetic reconnection on the duskside high-latitude magnetopause tailward of the cusp under mainly northward IMF.

Important questions related to the large-scale nature of the reconnection are its continuity in time and the location of the X-line on the magnetopause. The reconnection process is considered continuous if it continues for extended time without interruption, as opposed to intermittent reconnection. Continuity implies that the reconnection rate never drops to zero even though it can be variable. The variability in time of the reconnection rate determines whether the process is steady or unsteady. When the rate is almost constant in time, the reconnection is considered quasi-steady. At low latitudes for southward IMF in-situ evidence of long lasting reconnection flows on a time scale of few hours has been interpreted in terms of quasi-steady reconnection (Gosling et al., 1982; Phan et al., 2000; Marcucci et al., 2000). At high-latitude indications of continuous reconnection active for several hours have been obtained directly from in-situ observations by Phan et al. (2004) for southward IMF. Indirect evidence of continuous reconnection has been obtained from proton aurora measurements by Frey et al. (2003) with northward IMF and from radar measurements by Pinnock et al. (2003) with southward IMF. The possibility to infer the continuity of the reconnection process at the magnetopause from in-situ measurements is limited. The in-situ evidence, such as plasma jets or ion distribution functions on reconnected field lines, can be observed only during a short time interval when a spacecraft crosses the MP/BL. No information on the reconnection can be obtained when a spacecraft is well inside/outside the magnetosphere even if the process is actually going on continuously. Nevertheless, the possibility to have many simultaneous observations points as with Cluster reduces this limitation (Phan et al., 2004), especially for particularly favorable orbit and spacecraft configurations. As a result of such conditions in our study, we are able to obtain observations that are consistent with magnetic reconnection going on continuously for a period of about four hours.

Another important issue is the location of the X-line, a place where the reconnection is initiated. According to largescale models of reconnection, the location of the X-line is controlled by the relative orientation of the IMF and the Earth's magnetic field. Different models predict different locations of the X-line. In the antiparallel merging model (Crooker, 1979; Luhmann et al., 1984) the reconnection occurs in localized regions at the magnetopause where the magnetic fields are nearly antiparallel. On the other hand, in the component merging model (Sonnerup, 1974; Gonzalez and Mozer, 1974) the reconnection can occur even if only one component of the magnetosheath and magnetospheric magnetic field is oppositely directed. In general, it is difficult to conclude whether the component or the antiparallel merging model best describes the large-scale configuration of magnetic reconnection at the high-latitude magnetopause without knowing the location of the X-line, which has been inferred in a quantitative way using measurements in the Earth's magnetospheric cusp (Fuselier et al., 2000) and in a qualitative way using proton aurora measurements (Fuselier et al., 2002; Phan et al., 2003). On the basis of cusp aurora observations, Fuselier et al. (2002) concluded that under northward IMF high-latitude reconnection can be better explained by antiparallel merging. In this description the location of the X-line is limited to a localized region on the magnetopause and it depends on the value of the IMF $B_{Y}$ component i.e. the X-line moves to the dawn/dusk flank of the magnetopause for any finite dusk/dawn IMF $B_{Y}$ component. Nevertheless, recent observations show that at highlatitude with northward IMF antiparallel and component reconnection can occur at the same time (Trattner et al., 2004). In this interpretation reconnection occurs at the high-latitude magnetopause also where it is not predicted by the antiparallel merging model, the only difference being that the process is less efficient than in the antiparallel situation.

A good way to distinguish between the two models is to measure the magnetic shear in the vicinity of the X-line. This is in general difficult because passages close to the $\mathrm{X}$-line are rare. Nevertheless, in some fortuitous cases passages close to the reconnection site can be detected when ion jet reversals are observed (Avanov et al., 2001; Phan et al., 2003). In these cases a measurement of the local magnetic shear gives an indication of the shear at the X-line. Here we report two examples of X-line encounters detected using the observations of ion jet reversals. One of them has low magnetic shear which is inconsistent with antiparallel merging predictions.

In our study we present multispacecraft Cluster observations of high-latitude magnetic reconnection tailward of the cusp under northward IMF conditions. We find fluid and kinetic evidence of reconnection and we conclude that reconnection can be continuous for several hours and that the location of the X-line on the high-latitude magnetopause can be better explained by the component merging model.

The paper is structured in the following way. In Sect. 2 we describe the data set and the orbit/configuration of Cluster during the event. In Sect. 3 we describe the observations of the overall event while in Sect. 4 we concentrate on the selection and analysis of the accelerated flows. Section 5 describes the fluid and kinetic reconnection tests on the accelerated flows. Finally, in Sect. 6 we discuss the results and summarize them in Sect. 7.

\section{Data set and orbit}

In this study we present observations during the time interval 07:35-11:55 UT on 3 December 2001. We use data from the Cluster Ion Spectrometry (CIS) and the FluxGate Magnetometer (FGM) experiments on board Cluster 
spacecraft $\mathrm{SC} / 1, \mathrm{SC} / 3$ and $\mathrm{SC} / 4$. No data from CIS are available for $\mathrm{SC} / 2$. The CIS experiment consists of two different instruments: CODIF, which provides the threedimensional ion distribution function of four ions species $\left(\mathrm{H}^{+}, \mathrm{He}^{+}, \mathrm{He}^{++}\right.$and $\left.\mathrm{O}^{+}\right)$in the energy per charge range 20 $40000 \mathrm{eV} / \mathrm{e}$, and HIA which gives the ion three-dimensional distribution function in the energy per charge range 5$32000 \mathrm{eV} / \mathrm{e}$ with no mass separation (Reme et al., 2001). Both instruments have a time resolution up to the spacecraft spin period $(4 \mathrm{~s})$. Distribution functions and onboard moments with $4 \mathrm{~s}$ time resolution are used in this study. Data from CIS-HIA for ions are used for $\mathrm{SC} / 1$ and $\mathrm{SC} / 3$ while data from CIS-CODIF for $\mathrm{H}^{+}$are used for SC/4. The FGM experiment is described by Balogh et al. (2001). Spin-averaged magnetic field data with $4 \mathrm{~s}$ time resolution are used for all the spacecraft. Solar wind parameters have been obtained from the ACE spacecraft.

Figure 1 shows the Cluster orbit in the GSM $Y Z$ and $X Z$ planes during the event. The spacecraft are located in the duskside Southern Hemisphere and move, during the event, from $-65^{\circ}$ to $-50^{\circ}$ in GSM latitude and from 17:00 to 15:00 in GSM local time. The separation between the spacecraft during this event is several thousand kilometers in the GSM $Y Z$ plane (see the insert in Fig. 1) and is smaller along the $X_{G S M}$ direction (not shown), namely $500 \mathrm{~km}$ between SC1 and $\mathrm{SC} / 3$, and $1200 \mathrm{~km}$ between $\mathrm{SC} / 4$ and SC/3, with SC/3 always at the largest $X_{G S M}$.

\section{Observations}

\subsection{Event overview}

Figure 2 is a summary plot of the event in the interval 07:3511:55 UT. The four top panels show the ion energy spectrogram, the ion number density, the velocity components and magnetic field components in GSE for SC/1. The following panels show the same quantities for $\mathrm{SC} / 3$ and $\mathrm{SC} / 4$, respectively. Until 08:50 UT SC/4 was operating in the low sensitivity mode (it uses the hemisphere of the detector with the small geometrical factor). At the beginning of the interval all three spacecraft are in the magnetosheath. SC/1 and SC/4 have an inbound magnetopause crossing at approximately the same time, around 07:40 UT. After that time, during the whole event, they stay mainly on the magnetospheric side of the MP performing crossings of the current sheet mostly before 09:00 UT. Simultaneously with the SC/1 and SC/4 MP crossing at 07:40 UT, SC/3 goes from the magnetosheath into a turbulent sheath-like region close to the current sheet, as indicated by many partial crossings, staying there until 09:40 UT when the spacecraft has a complete MP crossing. This crossing is followed by several other crossings until the end of the event. As shown by the data, SC/3 spends more time than the other two spacecraft in the magnetosheath (from 07:40 to 09:40 UT and during several time intervals between 09:40 and 11:55 UT).

Two points are noteworthy. First, the orientation of the magnetospheric magnetic field $\left(B_{X}<0, B_{Y}>0, B_{Z}<0\right)$
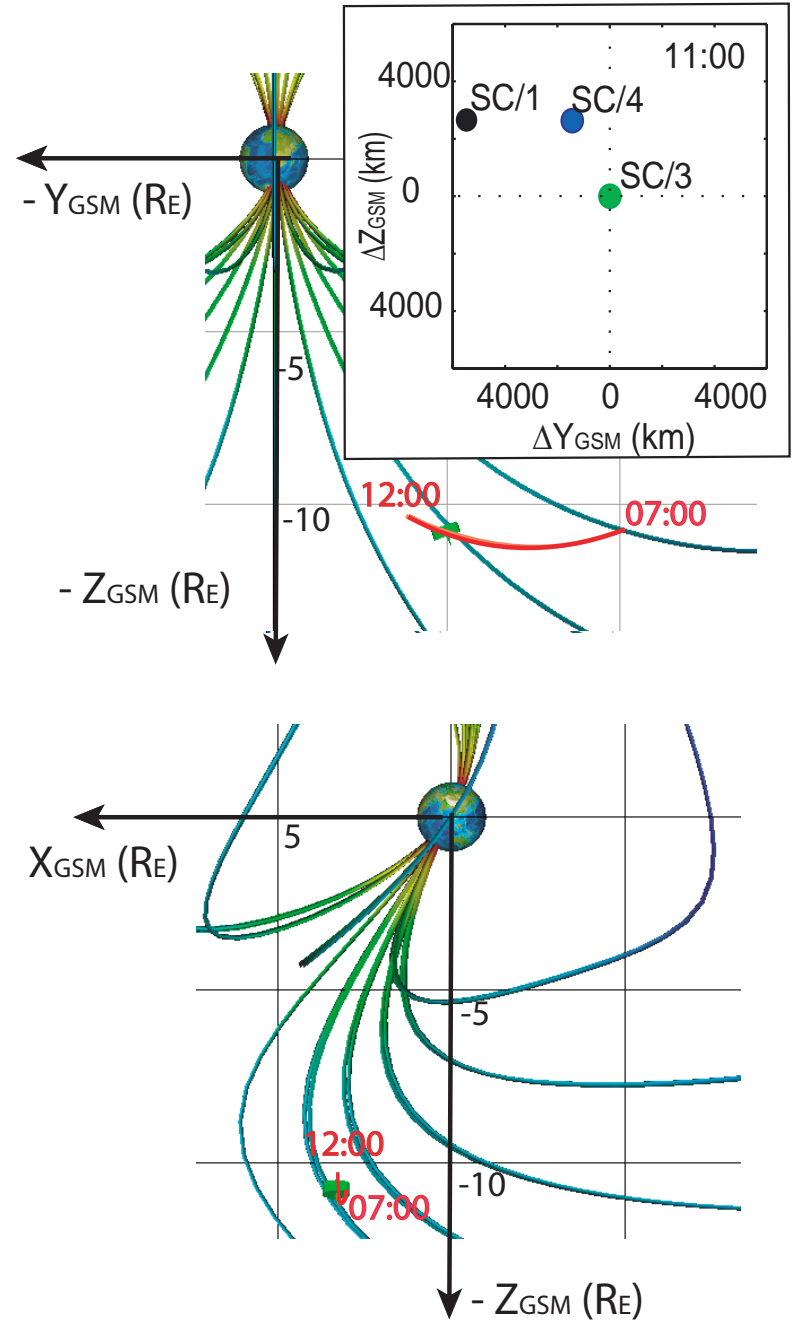

Fig. 1. SC/3 orbit on GSM $X Y$ and $Y Z$ planes from 07:00 UT to 12:00 UT on 3 December 2001. The spacecraft position corresponds to 11:00 UT. The insert shows SC/1 and SC/4 location respect to SC/3 on GSM $Y Z$ plane at 11:00 UT. The plot was created using the OVT program (http://ovt.irfu.se).

indicates that the spacecraft are located on the dusk side of the magnetopause tailward of the cusp. Secondly, due to the particular configuration of the spacecraft with respect to the magnetopause, at least one spacecraft is close to the magnetopause throughout the event. This shows a clear advantage of having multiple observation points in studies of reconnection as the number of current sheet encounters increases.

The main feature of this event is that during most of the magnetopause crossings, both complete and partial, the spacecraft observe "anomalous" flows in the MP/BL, namely flows which differ from the usual MP/BL flow, being either sunward flows in the opposite direction to the magnetosheath flow or antisunward jets with a speed larger than the magnetosheath speed. These flows are interpreted as being due to magnetic reconnection and are the subject of the present study. They will be discussed in Sects. 4 and 5 but first we describe the solar wind conditions. 


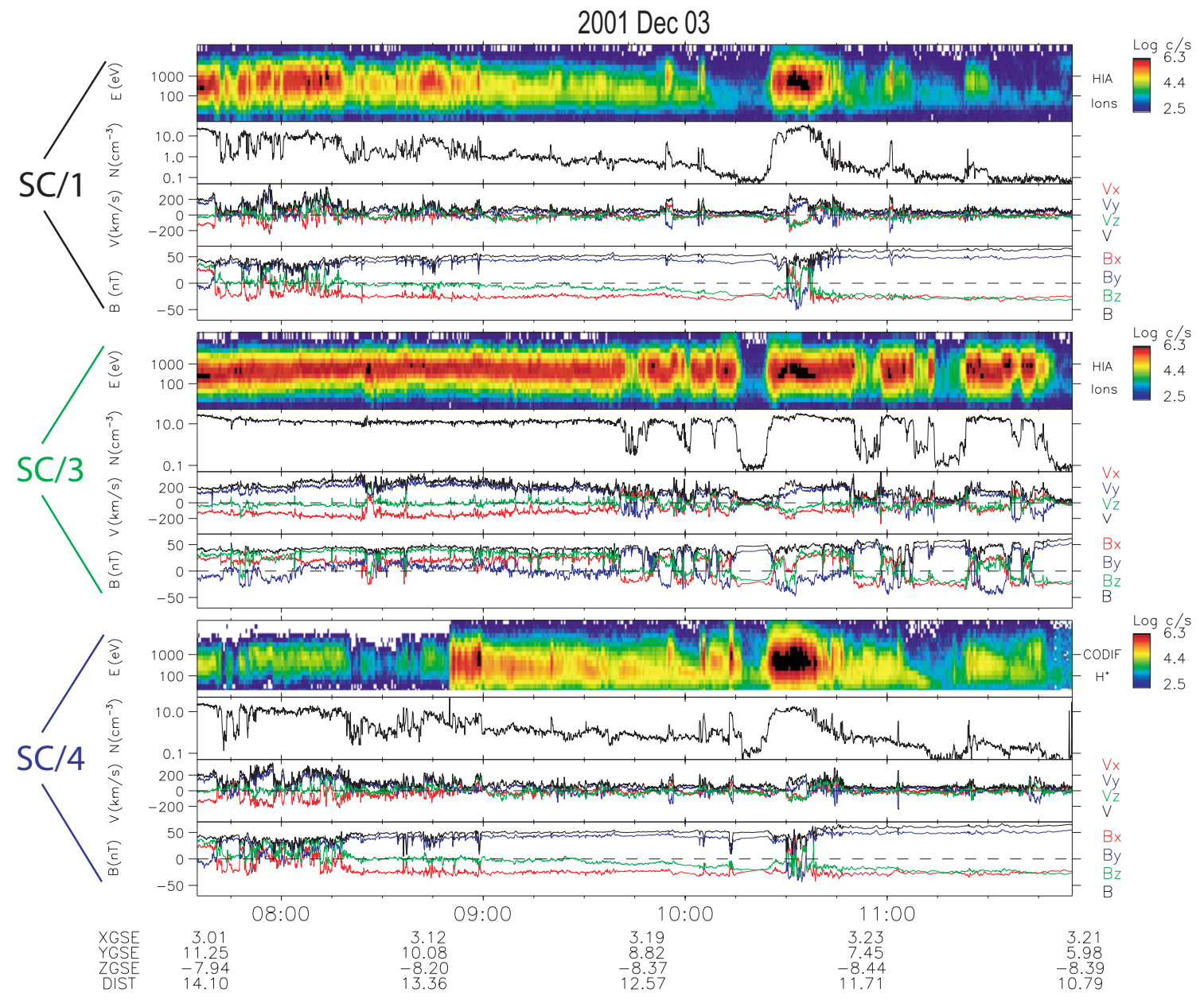

Fig. 2. Summary plot of the event from 07:35 to 11:55 UT . The four top panels show ion energy spectrogram, ion number density, ion velocity components and magnetic field components in GSE for SC/1. The following panels show the same quantities for SC/3 and SC/4, respectively.

\subsection{Solar wind conditions}

In this event we are in the ideal situation of having a nearby solar wind monitor directly in the magnetosheath: this is $\mathrm{SC} / 3$, which spends most of the time in the magnetosheath. The comparison between the magnetic field on $\mathrm{SC} / 3$ and on ACE has shown that, when $\mathrm{SC} / 3$ is in the magnetosheath, it sees similar features as ACE, although with variable delays. The IMF $B_{Z}$ is the dominant component and it stays mainly positive during the event (except for brief negative excursions). The IMF $B_{Y}$ is more variable, it is mainly positive or zero in the first part of the event (from 07:35 to 09:40 UT) and mainly negative in the second part (from 09:40 to 11:55 UT, except for an interval of positive values from 10:40 to 10:50 UT). For this reason the MP crossings have low magnetic shear in the earlier part of the event (i.e. before 09:40 UT) and high magnetic shear later.

Another important feature of the solar wind conditions is that the magnetosheath flow adjacent to the MP is sub-Alfvénic during most of the event. The Alfvénic Mach number $M_{A}$, calculated from $\mathrm{SC} / 3$ velocity (in the intervals when the spacecraft was in the magnetosheath) is quite low, typically about 0.5 , as one can see in Fig. 3 , for a short time interval.

\section{Examples of anomalous flows}

Figure 3 is an example of two complete magnetopause crossings, one inbound and one outbound, observed by SC/3 over a short time interval. At both crossings anomalous flows are present in the MP/BL. From 10:47:00 to 10:49:49 UT SC/3 is in the magnetosheath (except for a brief excursion in the MP between 10:48:45 and 10:49:37 UT). From 10:49:49 to 10:50:25 UT it performs a complete inbound crossing of the current sheet, as shown by the density and temperature gradient and by the magnetic field rotation. From 10:49:51 to 10:50:15 UT and from 10:50:27 to 10:50:39 UT SC/3 observes, respectively, an accelerated antisunward flow $\left(V_{X}<0\right.$, $\left.V_{Y}>0, V_{Z}<0\right)$ greater than adjacent magnetosheath values and a sunward flow $\left(V_{X}>0, V_{Y}<0, V_{Z}>0\right)$. Later, from 10:58:14 to 10:58:38 UT it crosses the current sheet for the 


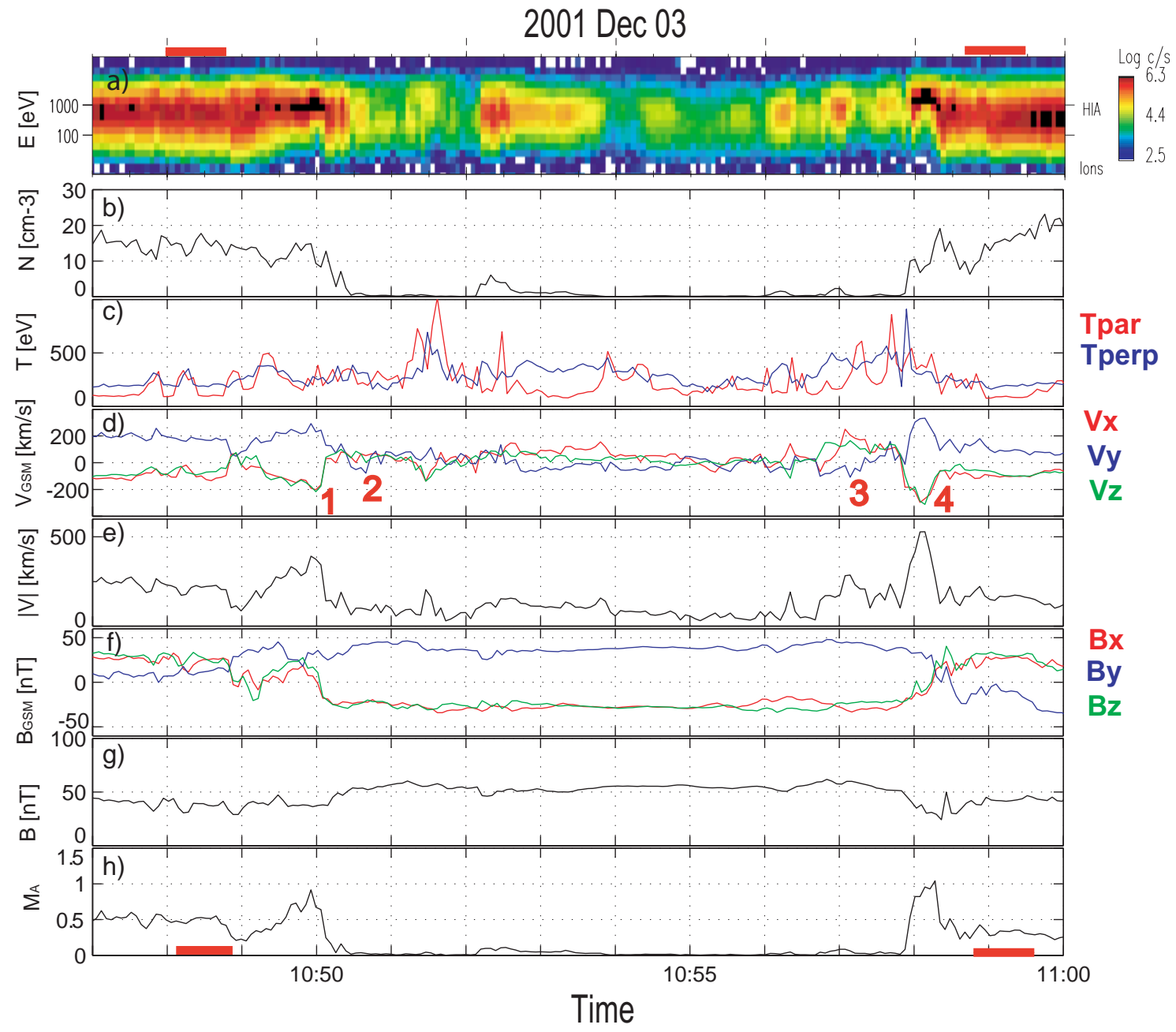

Fig. 3. Ion and magnetic field data for SC/3 in the time interval 10:47-11:00 UT. Panels show from top to bottom: (a) ion energy spectrogram, (b) ion number density, (c) parallel and perpendicular ion temperatures, (d) ion velocity components in GSM, (e) ion total velocity, (f) magnetic field components in GSM, (g) total magnetic field and (h) Alfvénic Mach number. Reconnection flows are indicated by red labels 1-4 while magnetosheath reference levels are shown by horizontal red bars.

second time, as shown again by the density and temperature gradient and by the magnetic field rotation. From 10:56:44 to 10:57:16 UT and from 10:57:52 to 10:58:16 UT SC/3 observes, respectively, a sunward flow $\left(V_{X}>0, V_{Y}<0, V_{Z}>0\right)$ and an accelerated antisunward flow $\left(V_{X}<0, V_{Y}>0, V_{Z}<0\right)$. Finally, after 10:58:38 SC/3 is in the magnetosheath.

The data described in Fig. 3 show examples of anomalous flows occurring in the MP/BL during complete magnetopause crossings (total rotation of magnetic field). Other anomalous flows occur during partial magnetopause crossings (partial or no rotation of magnetic field), usually when the spacecraft goes from the magnetosphere to the MP/BL without entering the magnetosheath proper.

Sunward directed flows $\left(V_{X}>0\right)$ are mainly observed in the BL while tailward flows $\left(V_{X}<0\right)$ are observed mainly in the MP. Both types of accelerated flows are the object of the present study and we interpret them in terms of high-latitude magnetopause reconnection. Such interpretation of sunward flows, directed in the opposite direction to the expected mantle/lobe velocity, has been done previously for other events (Gosling et al., 1991, 1996; Kessel et al., 1996; Safrankova et al., 1998; Avanov et al., 2001; Popescu et al., 2001; Phan et al., 2003).

\section{Evidence of magnetic reconnection}

In this section we discuss the fluid and kinetic evidence of magnetic reconnection. The fluid analysis is discussed in more detail while only qualitative considerations are given about the kinetic analysis. Also, the mutual consistency of both is briefly discussed.

\subsection{Fluid evidence of reconnection}

In order to test reconnection, the Walén test (Hudson, 1970; Paschmann et al., 1979, 1986; Sonnerup et al., 1981) was 


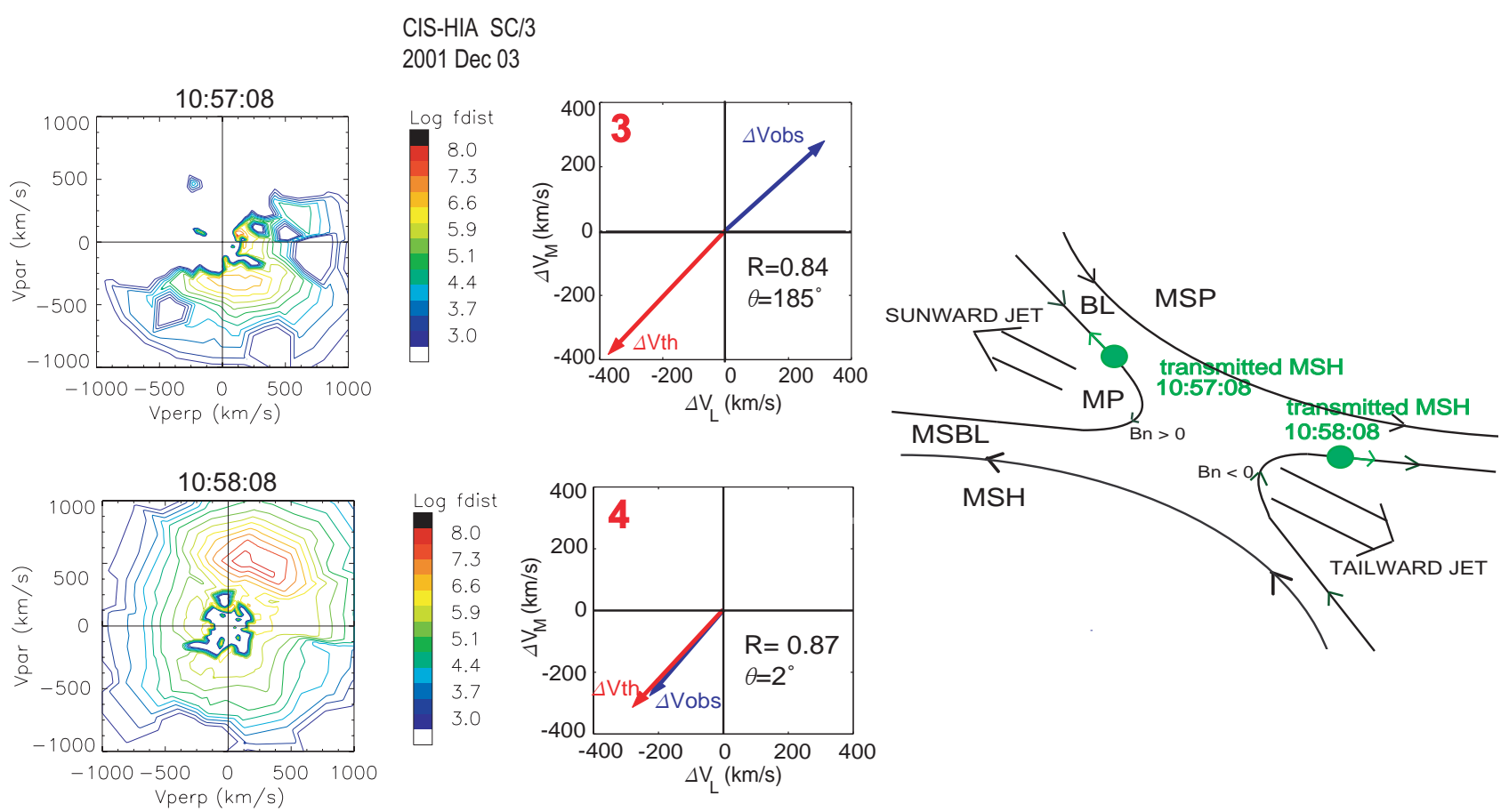

Fig. 4. D-shaped distribution functions on the $\left(V_{\perp}, V_{\|}\right)$plane and Walén test on the (L,M) plane for the flow reversal observed by SC/3 between 10:57:08 and 10:58:08 UT. $R$ is the ratio $\left|\Delta \boldsymbol{V}_{o b s}\right| /\left|\Delta \boldsymbol{V}_{t h}\right|$ while $\theta$ is the angle between the two vectors $\Delta \boldsymbol{V}_{o b s}$ and $\Delta \boldsymbol{V}_{t h}$ on the (L,M) plane. A perfect agreement would result in antisymmetric vectors for the sunward jet $\left(R=1, \theta=180^{\circ}\right)$ and overlapping vectors for the tailward jet $\left(R=1, \theta=0^{\circ}\right)$. The reconnection geometry is sketched on the right.

performed. In this test the tangential stress balance for a rotational discontinuity is achieved comparing the two vectors $\Delta \boldsymbol{V}_{t, o b s}=\boldsymbol{V}_{2 t}-\boldsymbol{V}_{1 t}$ and

$\Delta \boldsymbol{V}_{t, t h}= \pm\left[\left(1-\alpha_{1}\right) \mu_{0} \rho_{1}\right]^{1 / 2} \cdot\left[\boldsymbol{B}_{2 t}\left(1-\alpha_{2}\right)-\boldsymbol{B}_{1 t}\left(1-\alpha_{1}\right)\right]$

where $\boldsymbol{V}$ is the bulk velocity, $\rho$ the density, $\boldsymbol{B}$ the magnetic field and $\alpha=\left(p_{\|}-p_{\perp)} \mu_{0} / B^{2}\right.$ the pressure anisotropy factor. The subscript $t$ indicates the component of a vector in the plane tangent to the magnetopause while the subscripts $t h$, $o b s$ indicates theoretical and observed values, respectively. The two vectors are evaluated in the local $(\mathrm{L}, \mathrm{M})$ plane tangent to the magnetopause (Russell and Elphic, 1978) and calculated in a magnetosheath reference point (subscript 1) and in a point in the MP/BL (subscript 2).

As an example of Walén test, we perform the Walén analysis for the interval 10:47:00-11:00 UT, shown in Fig. 3. This interval includes a complete inbound crossing around 10:50 UT and a complete outbound crossing around 10:58 UT. Two local reference intervals (indicated in Fig. 3 by horizontal red bars) are used, the first from 10:48:23 to 10:48:47 UT, and the second from 10:58:48 to 10:59:37 UT. With the first reference level we have tested the two jets at 10:50:03 UT (antisunward) and 10:50:36 UT (sunward) labelled, respectively, 1 and 2 in Fig. 3 while with the second reference level we have tested the two jets at 10:57:08 UT (sunward) and 10:58:08 UT (antisunward) labelled 3 and 4 in the same figure. The result of the Walén test shows an excellent agreement with the theoretical predictions for reconnection at all four jets, as reported in Fig. 4, central panels, for jets 3 and 4 , where $\Delta \boldsymbol{V}_{t, o b s}$ and $\Delta \boldsymbol{V}_{t, t h}$ are drawn in the local (L,M) plane. The ratio $R=\left|\Delta \boldsymbol{V}_{t, o b s}\right| /\left|\Delta \boldsymbol{V}_{t, t h}\right|$ and the angle $\theta$ between the two vectors is also reported for the two jets 3 and 4 . The other panels of Fig. 4 will be discussed in Sect. 5.2.

The Walén test has been performed across all the complete MP crossings using a local reference level. It was decided to exclude from the Walén test the interval in which SC/4 was operating in low sensitivity mode (namely before 08:50 UT), although also in this interval SC/4 detects anomalous flows. In low sensitivity mode two polar sectors are absent; this has only a limited impact on moment calculation in the magnetosheath and magnetosphere but could strongly affect the moments in the case of anomalous flows.

$\mathrm{SC} / 1$ and SC/4 detect anomalous flows not only during the complete MP crossings, but also during occasional passes into the BL from the magnetosphere. These passes occur mainly between 8:30-10:15 UT, and are identified by a density gradient. The magnetic field rotation is partial or absent. The Walén analysis can be performed also on these partial crossings because $\mathrm{SC} / 3$ continuously provides a reference level in the magnetosheath. So even in the absence of a substantial rotation of the magnetic field, the Walén test can be performed across the MP between a point in the BL observed by $\mathrm{SC} / 1$ or $\mathrm{SC} / 4$ and a point in the magnetosheath, simultaneously observed by SC/3. This procedure assumes that over the separation of the spacecraft (few thousands kilometers) 


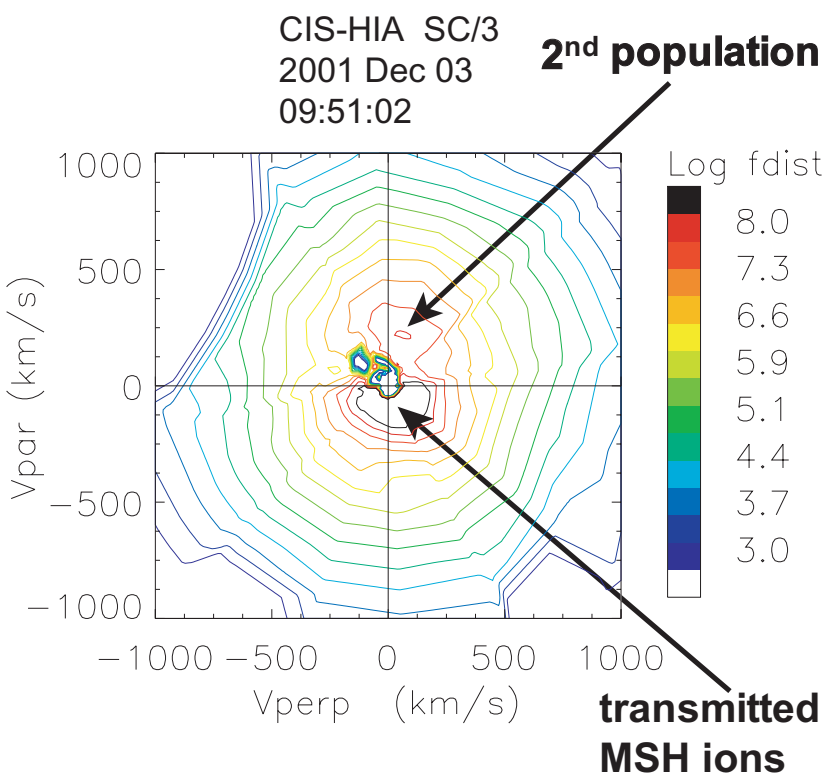

Fig. 5. $\mathrm{SC} / 3$ ion distribution function on the $\left(V_{\perp}, V_{\|}\right)$plane at 09:51:02 UT when the spacecraft is in the current sheet. A second population parallel to the magnetic field is present besides the transmitted magnetosheath ions.

the conditions in the magnetosheath are mainly unchanged.

When testing reconnection on all the complete and partial MP encounters, it was found that, while the Walén test is generally well satisfied in the outer part of the BL which is close to the MP (i.e. close to the field rotation), it usually becomes worse both in the MP and in the inner part of the $\mathrm{BL}$ close to the magnetosphere proper. The poor result of the Walén test in the inner BL/magnetosphere is qualitatively in agreement with previous analysis (Phan et al., 2001). A possible explanation of the worsening of the test in the MP is that quite often, besides the expected transmitted magnetosheath ions, additional populations (which are being investigated in detail in an ongoing study) are observed inside the MP. As an example, HIA observations during an MP crossing of $\mathrm{SC} / 3$ at 09:51:02 UT are shown in Fig. 5. Two populations are present: one antiparallel to the magnetic field, which we interpret to be the transmitted magnetosheath population, and a second population. The Walén test considerably improves if the moments of the distribution function are computed after removing the second population. This has been verified in a few, but representative, examples, as shown in Table 1. The improvement of the Walén test after the removal of the second population is consistent with the interpretation in terms of magnetic reconnection because the effect of the additional population is to modify the bulk velocity used in the Walén test (Gosling et al., 1996).

The results of the Walén analysis for the whole event are reported in Fig. 6c as a function of time. This figure is meant to illustrate in a synthetic way the results of the analysis for this long lasting event with numerous MP crossings observed by the three spacecraft. At each complete or partial
Table 1. Result of Walén test before and after the removal of the second population for some reconnection jets observed by SC/3.

\begin{tabular}{ccccc}
\hline & $\left|\triangle \boldsymbol{V}_{\text {obs }}\right| /\left|\Delta \boldsymbol{V}_{t h}\right|$ & \multicolumn{2}{c}{$\theta$} \\
\hline Time & before & after & before & after \\
\hline 09:51:02 & 0.73 & 0.86 & 221 & 170 \\
$09: 57: 51$ & 0.18 & 0.58 & 194 & 180 \\
$09: 58: 39$ & 0.40 & 0.62 & 177 & 170 \\
$11: 36: 51$ & 0.28 & 0.76 & 156 & 174 \\
$11: 37: 51$ & 0.38 & 0.65 & 152 & 180 \\
\hline
\end{tabular}

magnetopause crossing, the ratio $R$ and the angle $\theta$ defined above have been evaluated between a reference level in the magnetosheath (subscript 1 in Eq. 1) and each data point of an anomalous flow inside the MP/BL (subscript 2 in Eq. 1). In order to ensure that we are considering plasma of magnetosheath origin, a density criterion was applied, and only BL intervals with $n>1 \mathrm{~cm}^{-3}$ were considered. To assure an acceptable degree of confidence on the analysis results we consider the Walén test to be satisfied if the magnitude of the ratio $R$ differs by less than 0.3 from unity and the angle differs by less than $20^{\circ}$ from its theoretical value $\left(0^{\circ}\right.$ or $\left.180^{\circ}\right)$. For each interval of anomalous flow satisfying the Walén relation, only the point with the best value of $R$ and $\theta$ has been retained and reported in Fig. 6c. In this figure each point is represented by a segment with magnitude equal to $R$ and inclination equal to the same angle as that between $\Delta \boldsymbol{V}_{o b s}$ and $\Delta \boldsymbol{V}_{t h}$ on the (L,M) plane. Notice that several such segments can correspond to one MP crossing. Complete (partial) MP crossings are indicated by full (dashed) lines. A perfect Walén test with a plus (minus) sign, namely with an inward (outward) $B_{n}$ component, would give a vertical segment of unit length, pointing up (down) for antisunward (sunward) flows. The horizontal black lines indicate intervals in which all three spacecraft are far from the current sheet (either in the magnetosheath, or in the magnetosphere). Note that panels (a) and (b) of Fig. 6 will be described in Sect. 6.3.

Figure $6 \mathrm{c}$ shows that reconnection flows are observed throughout the event by the three spacecraft. Indeed, out of 27 complete magnetopause crossings observed by the three spacecraft, 22 show accelerated flows which satisfy the Walén relation. Of the remaining five crossings, three are outbound magnetopause crossings experienced by the three spacecraft around 10:25 UT, possibly associated to a brief southward turning of the IMF when reconnection is not expected to occur tailward of the cusp. Moreover, one crossing of the BL (SC/3 at 09:59 UT) is possibly too fast to be able to detect jets, and the other (SC/3 at 11:05:38 UT) is slightly below our selection criteria $\left(R=0.66, \theta=159^{\circ}\right)$.

Most of the observed jets flow sunward, consistent with the reconnection site being tailward of the spacecraft. Few antisunward flows are also observed, indicating that the reconnection site was sometimes sunward of the spacecraft. Tailward flows are detected mainly by SC/3, consistent with 


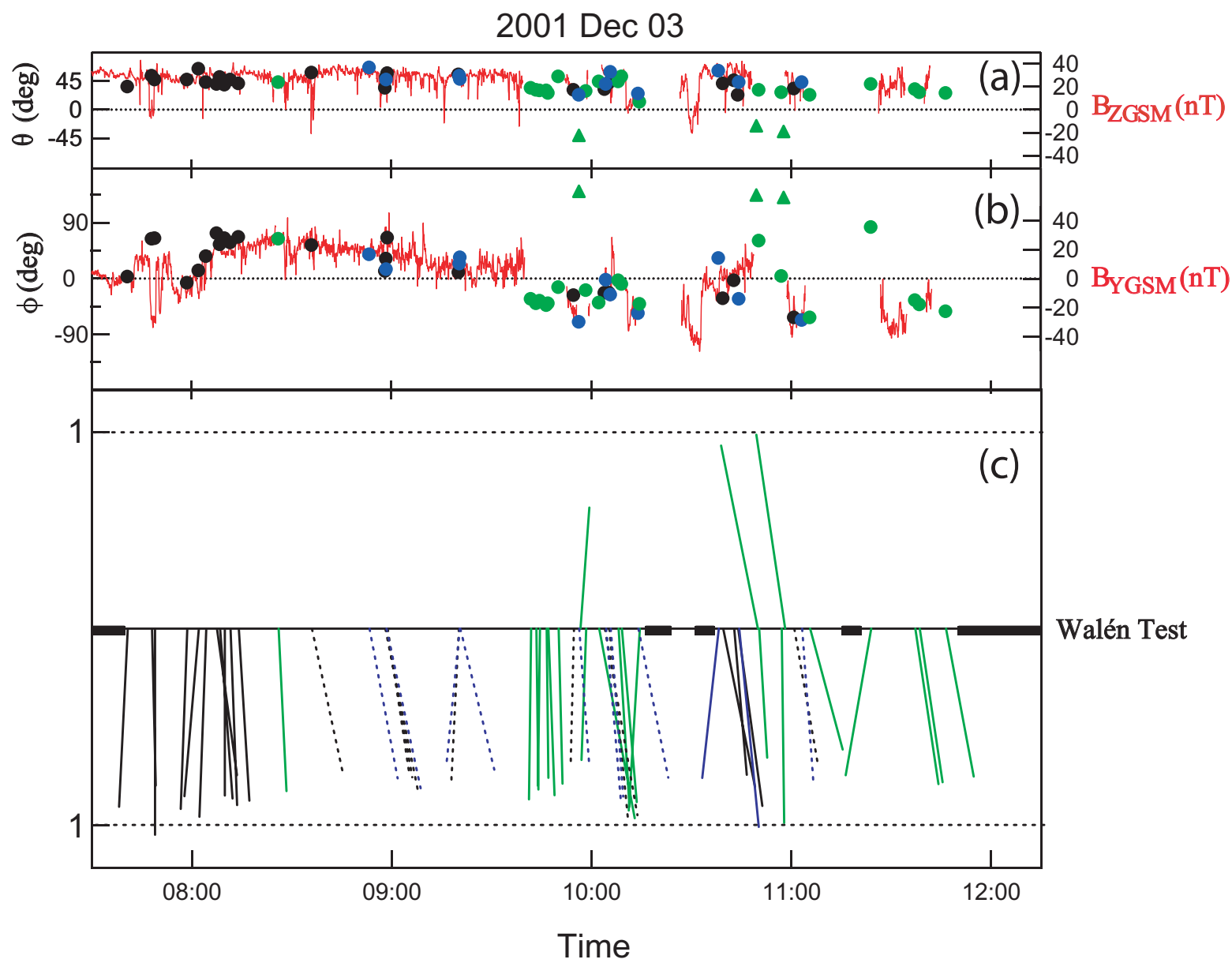

Fig. 6. Walén test and direction of the reconnection jets. (a) Superposed latitude $\theta_{G S M}$ and SC/3 $B_{Z} G S M$, (b) superposed longitude $\phi_{G S M}$ and SC/3 $B_{Y} G S M$, (c) temporal history of the Walén test during the event. Sunward flows are indicated by circles while antisunward flows by triangles. SC/1 data are in black, SC/3 data in green, SC/4 data in blue. Reconnection jets associated with complete/partial crossings are indicated by full/dashed lines. A perfect Walén test would give a vertical vector of unit length, pointing up (down) for antisunward (sunward) flows. Horizontal black bars indicate intervals when all the SCs are far from the MP/BL.

its position being more tailward with respect to the other spacecraft and therefore being more favorable to detect tailward flows.

\subsection{Kinetic evidence of reconnection}

Several kinetic signatures typical of reconnection (Cowley, 1995) have often been observed during this event: (1) Dshaped distribution function of transmitted magnetosheath ions in the MP/BL; (2) incident/reflected magnetosheath ions in the magnetosheath boundary layer (MSBL). D-shaped distribution functions are expected in the MP/BL with a lowenergy cutoff at a velocity $V_{\|}$along the magnetic field equal to the parallel component of the deHoffmann-Teller velocity (Cowley, 1982). These distributions functions, although not present at all reconnection flow events on this day, have been observed in many cases. For example, in the partial MP crossing around 09:55 by $\mathrm{SC} / 1$ and $\mathrm{SC} / 4$, all the distribution functions (during about $1 \mathrm{~min}$ ) are D-shaped. Two examples are shown in Fig. 4 for SC/3 at 10:57:08 and 10:58:08 UT. The distributions show a low energy cut-off at a velocity parallel to the magnetic field with $V_{\|}<0$ at 10:57:08 UT (sunward flow i.e. $B_{n}>0$ ) and $V_{\|}>0$ at 10:58:08 UT (tailward flow i.e. $\left.B_{n}<0\right)$. In this figure a sketch of the reconnection geometry is also shown. An explicit calculation of the deHoffman-Teller reference frame for the tailward flow shows good agreement with theoretical expectations of $V_{\|}-V_{H T \|} \approx 280 \mathrm{~km} / \mathrm{s}$ and $V_{c u t \|} \approx 250 \mathrm{~km} / \mathrm{s}$, where $V_{c u t \|}$ is the observed cut-off along the magnetic field in the distribution function at 10:58:08 UT.

We also observe incident/reflected magnetosheath ions in the MSBL in some cases. The reflected magnetosheath ions are expected to flow in the MSBL along the magnetic field lines in the opposite direction to the incident population. One example is shown in Fig. 7 for SC/3. Incident and reflected populations have the expected velocities $V_{i \|}<0$ and $V_{r \|}>0$ for a MSBL adjacent to a sunward jet $\left(B_{n}>0\right)$, as shown in the sketch of the reconnection geometry. 


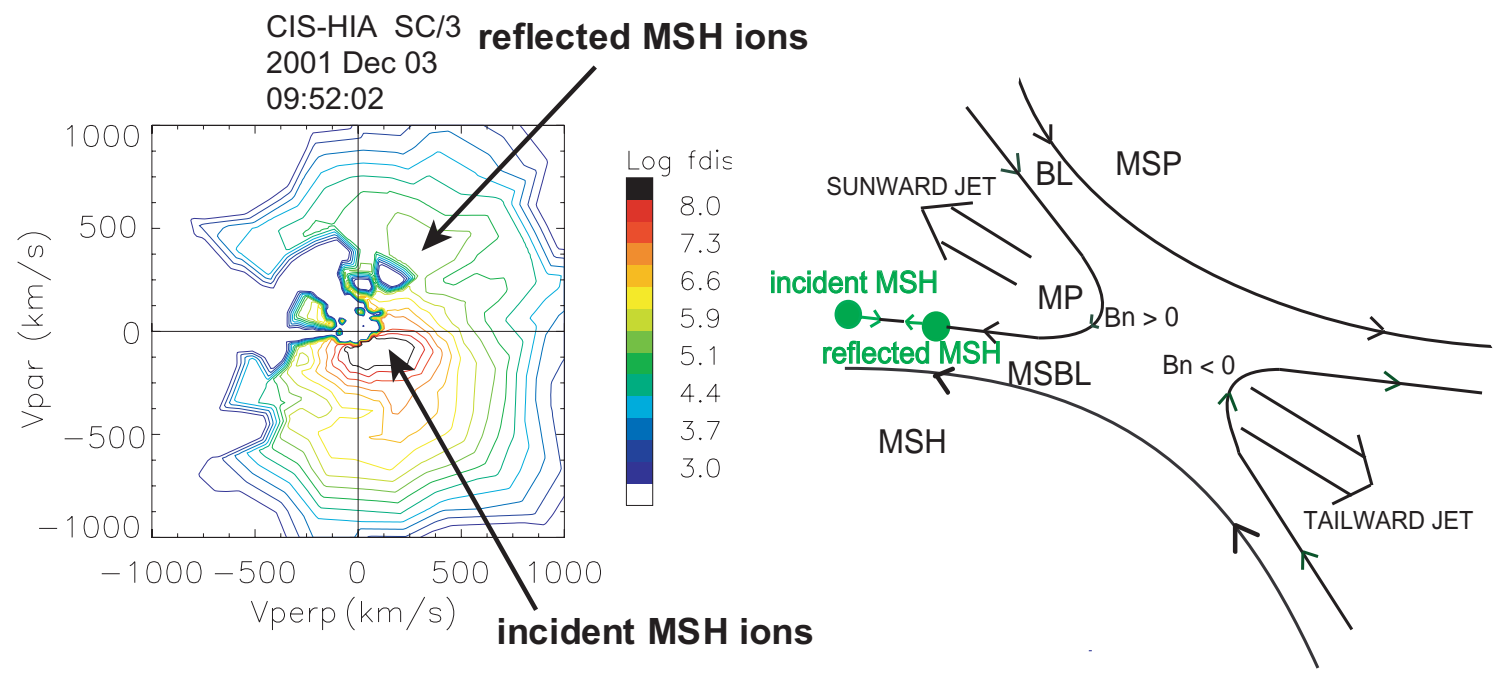

Fig. 7. SC/3 ion distribution function on the $\left(V_{\perp}, V_{\|}\right)$plane at 09:52:22 UT when the spacecraft is in the MSBL. Incident and reflected populations are shown, as well as a sketch of the reconnection geometry.

\subsection{Consistency between fluid and kinetic evidence}

Fluid and kinetic signatures of magnetic reconnection are both observed during this event but with larger occurrence for fluid evidence, in agreement with previous studies (Bauer et al., 2001). In a few cases both evidence is observed at the same time showing mutual consistency: (a) for sunward flows: Walén relation satisfied with negative sign (implying $B_{n}>0$, i.e. crossing sunward of the reconnection site), Dshaped distribution functions in the MP/BL, with cut-off at $V_{\|}<0$, and incident/reflected MSBL populations with $V_{i \|}<0$ and $V_{r \|}>0$; (b) for tailward flows: Walén relation satisfied with positive sign (implying $B_{n}<0$, i.e. crossing tailward of the reconnection site), D-shaped distribution functions in the MP/BL with cut-off at $V_{\|}>0$.

\section{Discussion}

\subsection{Evidence of magnetic reconnection}

During about four hours the Cluster spacecraft, separated by a distance of a few thousands kilometers, observe anomalous flows, i.e. either sunward flows in the direction opposite to the magnetosheath flow or antisunward jets with a speed larger than the magnetosheath speed. These flows are in agreement with the occurrence of magnetic reconnection, as shown by the satisfactory result of the Walén test (fluid evidence). Kinetic signatures, in the form of D-shaped distribution functions for transmitted magnetosheath ions in the MP/BL and of incident/reflected magnetosheath ions in the MSBL, also confirm this interpretation in some cases. Fluid evidence is observed more often than kinetic evidence. When the two pieces of evidence are found together, they show mutual consistency.

Additional ion populations, other than the expected transmitted magnetosheath ions, are often present in the MP and in those cases the Walén test gives poor agreement, but after their removal from the distribution function the Walén test shows a general improvement. This is consistent with theoretical expectations, if additional ion populations do not cross the magnetopause (Gosling et al., 1996). The detailed study of these additional populations is the subject of an ongoing study.

Finally, it is important to notice that sunward flows can be observed during this event because of a quite low Alfvénic Mach number $(\approx 0.5)$ in the magnetosheath throughout the event. This condition is expected to hold for observation of sunward convection in the lobes as result of high-latitude reconnection tailward of the cusp (Gosling et al., 1991; Popescu et al., 2001).

\subsection{Continuity of the reconnection process}

The orbit and the configuration of the spacecraft during this event are just ideal to address the continuity issue. The spacecraft are skimming the MP in such a way that for most of the time $\mathrm{SC} / 3$ is close to the MP on the magnetosheath side while $\mathrm{SC} / 1$ and SC/4 are in the BL. The separation between the spacecraft is of the order of the magnetopause thickness, i.e. about one thousand kilometers, so that normally at least one spacecraft is inside the magnetopause. Only during a few time intervals were all three spacecraft well inside the magnetosphere or well outside in the magnetosheath. As a result of this convenient combination of spacecraft configuration and orbit, the number of MP/BL encounters increased, resulting in an excellent coverage of the magnetopause.

We argue that our observations are consistent with continuous reconnection occurring at the high-latitude magnetopause during about four hours. Figure $6 \mathrm{c}$ shows that reconnection flows are repeatedly detected throughout the time of observations. They are observed at all complete MP crossings (except at five crossings discussed earlier) and, thanks 

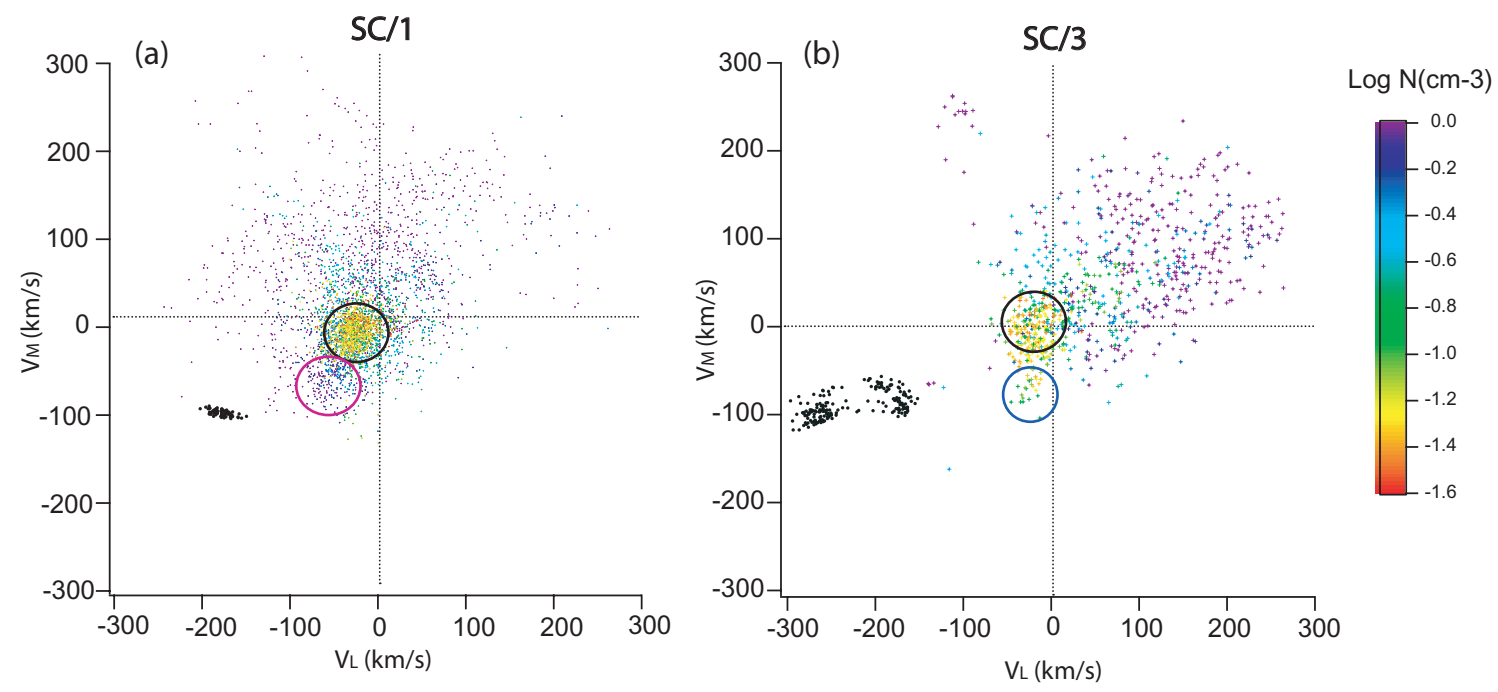

Fig. 8. Scatter plot of SC/1 (left) and SC/3 (right) ion flow velocity for all the magnetosphere and boundary layer passages. Color coding corresponds to the logarithm of the ion number density. The black dots are representative of magnetosheath flow. See the text for the description of circles.

to Cluster's configuration, also at many partial crossings of $\mathrm{SC} / 1$ and SC/4 so that, all together, a large number of reconnection flows are detected during four hours. This strongly suggests that reconnection can be continuous. Of course, one cannot exclude the possibility that the reconnection process ceases between the jets, which usually corresponds to time intervals when the spacecraft are far from the MP/BL (black horizontal bars in Fig. 6c). If reconnection is continuous, reconnection flows should be present every time the spacecraft are in the MP/BL. This condition cannot be tested quantitatively for all the anomalous flows observed in the MP/BL, first because they correspond to too many data points, and second because it is difficult to exclude data points in the inner BL/magnetosphere, where the Walén test is not expected to work. Nevertheless, in Fig. 8 we show a qualitative indication that most of the time the spacecraft are in the BL they observe anomalous sunward directed flows while they do not observe them in the magnetosphere proper. Figure 8 shows a scatter plot of $\left(V_{L}, V_{M}\right)$ ion flow velocity for all the magnetosphere and $\mathrm{BL}$ passes. The magnetosphere proper has been schematically identified as the region of dipole magnetic field with ion density smaller than $1 \mathrm{~cm}^{-3}$, while the $\mathrm{BL}$ is identified as the region of dipole-like magnetic field with ion density greater than $1 \mathrm{~cm}^{-3}$. The data points are color coded according to the corresponding density. The left panel refers to $\mathrm{SC} / 1$ and the right panel to $\mathrm{SC} / 3$. The black dots in the lower left quadrant of each plot are representative of magnetosheath flow. Points inside black circles and inside the blue circle are flows in the magnetosphere and in the mantle. It is found that apart from a few points, indicated by a red circle in panel (a), SC/1 and SC/3 observe sunward anomalous flows whenever they are in the BL, but not in the magnetosphere proper, where the velocity has the typical features of the mantle/lobe velocity.
It is important to stress that the Walén test gives no information about the reconnection rate. As long as continuous reconnection jets are observed, one can only conclude that the reconnection process is continuous in time (i.e. the reconnection rate is different from zero). However, this does not imply a steady reconnection because the reconnection rate can still be modulated in time (Phan et al., 2004).

\subsection{IMF control of reconnection on large scale}

Mainly sunward flows are observed during the event, implying that an X-line is located tailward of the spacecraft most of the time. Because spacecraft are located tailward of the cusp this is consistent with the X-line being tailward of the cusp, in agreement with mainly northward IMF conditions. A few tailward flows are observed by SC/3 sometimes indicating an $\mathrm{X}$-line sunward of the spacecraft.

Figure 6 shows the flow directions of each reconnection event in terms of latitude $\theta_{G S M}$ (panel a) and longitude $\phi_{G S M}$ (panel b), defined on the $X Y_{G S M}$ plane to be zero for $Y_{G S M}=0$ and positive in the anticlockwise direction. The IMF $B_{Z}$ and $B_{Y}$ components (measured by $\mathrm{SC} / 3$ in the magnetosheath) are also shown, superposed, respectively, on $\theta_{G S M}$ and on $\phi_{G S M}$. The antisunward flows are observed with $\theta_{G S M}<0^{\circ}$ and $\phi_{G S M}>90^{\circ}$. The sunward flows are instead observed with $\theta_{G S M}>0^{\circ}$ and $\phi_{G S M}$ from positive/zero (before 09:40 UT) to negative (after 09:40 UT), with an absolute value less than $90^{\circ}$. The sign of $\phi_{G S M}$ seems to follow the change in the sign of the IMF $B_{Y}$, from positive during the first part of the event to negative during the second part. Therefore, the pattern of the flow directions during the whole event is consistent with the orientation of the reconnecting IMF. This indicates that the reconnection process is globally controlled by the IMF rather than being a local random process (Nishida, 1989). 


\subsection{Component vs. antiparallel merging}

It is possible to qualitatively distinguish between antiparallel and component merging when spacecraft are close to the Xline because the relevant parameter is the magnetic shear at the $\mathrm{X}$-line. Ion jet reversals have been interpreted as a possible indication of the spacecraft passage close to the X-line (Gosling et al., 1991; Avanov et al., 2001; Phan et al., 2003). Figure 3 shows two jet reversals observed by $\mathrm{SC} / 3$ on a time interval of about 10 min. The first one, around 10:50 UT, shows a passage from a tailward jet (indicated by the label 1 in the figure) to a sunward jet (label 2) while the second, around 10:58 UT, shows a passage from a sunward jet (label 3) to a tailward jet (label 4). All four observed flows are consistent with the occurrence of magnetic reconnection and both fluid and kinetic evidence (D-shaped distribution functions) have been found. Thus, we interpret these two jet reversals as passages of $\mathrm{SC} / 3$ close to the $\mathrm{X}$-line.

As one can see from the figure the first MP crossing at 10:50 UT has low shear $\left(100^{\circ}\right)$, being $B_{Y}>0$ while the second one has high shear $\left(160^{\circ}\right)$, being $B_{Y}<0$ instead. Taking the jet reversals as indications of passages close to the reconnection site one can regard the measured shear to be close to the shear at the X-line. For crossings 1 and 2 the observations seem to be more consistent with component merging because of the small shear measured close to the reconnection site. The fact that the velocities (both tailward and sunward) observed during crossings 1 and 2 are smaller than those observed during crossings 3 and 4 is also consistent with component merging because of the weaker "kick" experienced by the injected ions compared to the antiparallel situation (Trattner et al., 2004). A sketch of component merging for this event is given in Fig. 9, where the reconnection geometry on the duskside is shown. Observations of sunward flows with $\theta_{G S M}>0^{\circ}$ and $\phi_{G S M}>0^{\circ}$ are consistent with component merging, for which freshly opened field lines cannot give enough "kick" to the ions to flow in the $\phi_{G S M}<0^{\circ}$. The observations of reconnection flows far out on the dusk side of the magnetopause, irrespective of the change in the IMF $B_{Y}$, also support component merging as discussed below.

In the second part of the event (after 09:40 UT), while IMF $B_{Y}$ stays mainly negative, jets are recorded in the sunwarddawnward $\left(\phi_{G S M}<0^{\circ}\right)$ and northward $\left(\theta_{G S M}>0^{\circ}\right)$ direction, except in three cases when tailward jets are recorded by SC/3. This is consistent with reconnection site located almost always tailward and southward of the spacecraft during this interval. The local shear measured by the spacecraft in this part of the event is close to the antiparallel prediction, apart from the time interval 10:40-10:50 UT, during which IMF $B_{Y}$ is positive. In this situation it is not possible to distinguish between the antiparallel and component merging models, which both predict an X-line in the Southern Hemisphere on the dusk flank where the spacecraft are located.

In the first part of the event (before 09:40 UT) jets are directed northward $\left(\theta_{G S M}>0^{\circ}\right)$ but now $\phi_{G S M} \geq 0^{\circ}$, i.e. jets are directed sunward and duskward. This is consistent again with a reconnection site located tailward and southward of (a)

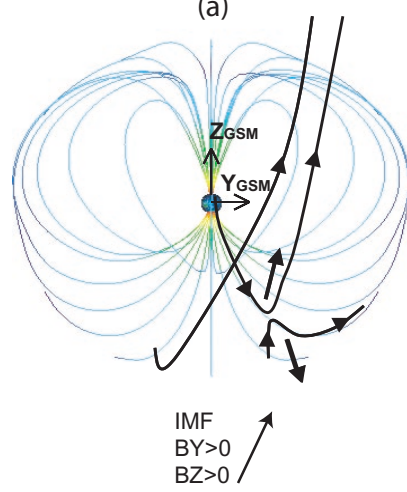

(b)

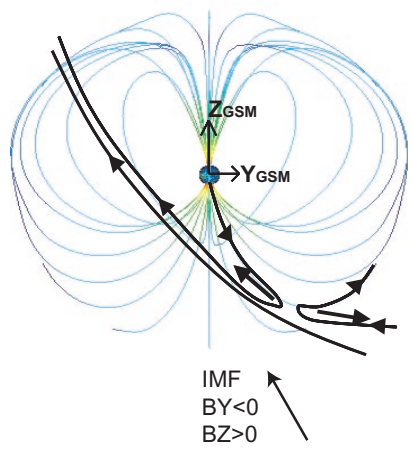

Fig. 9. Reconnection configuration for the two orientations of IMF. (a) IMF $B_{Z}>0, B_{Y}>0$, (b) IMF $B_{Z}>0, B_{Y}<0$. The jet directions are represented by the arrows.

the spacecraft. During this interval the IMF $B_{Y}$ is mainly positive. For this orientation of the IMF the antiparallel merging predicts an X-line on the dawn side of the magnetopause in the Southern Hemisphere, i.e. on the opposite side of where the spacecraft are located. Cluster is located at $Y_{G S M}=5-10 R_{E}$ which is far from the possible antiparallel reconnection site. According to component merging reconnection could still occur on the dusk side of the magnetopause, close to the Cluster location. The local shear measured by the spacecraft in this part of the event is far from the antiparallel prediction. Nevertheless this evidence cannot be used to conclusively rule out antiparallel merging, except for the case of flow reversals, because the X-line could be far away from the spacecraft and no information about the distance from the $\mathrm{X}$-line is available.

\section{Summary and conclusions}

In this paper we analyze, in detail, Cluster observations at the high-latitude duskside magnetopause on 3 December 2001. We show fluid and kinetic evidence of magnetic reconnection which strongly suggests that reconnection is continuous for a period of about four hours:

1. The fluid evidence is substantiated by the good agreement of the observed accelerated flows with the tangential stress balance between the magnetosheath and the magnetopause/magnetospheric boundary layer (Walén test). The kinetic evidence consists of the observation of D-shaped ion distribution functions in some reconnection flows in the magnetopause/magnetospheric boundary layer and of observations of incident/reflected magnetosheath ions in the magnetosheath boundary layer. When found together, fluid and kinetic evidence are consistent with each other.

2. Inside the magnetopause, besides the expected transmitted magnetosheath ions, the ion distribution functions often show additional populations. The Walén test 
improves after their removal from the distribution function, as shown in a few cases.

3. Observations are consistent with magnetic reconnection going on continuously for about four hours whenever the IMF is northward. Most of the time when no reconnection flows are observed the spacecraft are far from the magnetopause. The extended time coverage was possible due to the particularly favorable orbit and configuration of the spacecraft during this event. Out of a total number of 27 all but 5 complete magnetopause crossings are associated with reconnection flows. The other observed reconnection flows are associated with partial magnetopause crossings.

The observations are consistent with large-scale IMF control of magnetic reconnection and suggest a better agreement with component merging model:

1. During the event the IMF is mainly northward and the observations are consistent with magnetic reconnection occurring tailward of the cusp, as expected. Mainly sunward flows are observed during the event, implying that an X-line is located tailward of the spacecraft most of the time.

2. Flow directions during the event are consistent with the orientation of the reconnecting IMF. Observations are not consistent with patchy reconnection.

3. Observations of a few ion flow reversals indicate passages of the spacecraft close to the X-line.

4. During one of the flow reversals we observe low magnetic shear across the magnetopause on the side of the magnetosphere where an X-line is not predicted by antiparallel merging model. The observed low shear is consistent with a component merging model. The observations of reconnection flows far out on the dusk side of the magnetopause, irrespective of a change in the sign of the IMF $B_{Y}$, also suggest component merging model but they cannot be used to conclusively exclude antiparallel merging because the $\mathrm{X}$-line could be far away from the spacecraft.

Acknowledgements. We thank the ACE/MAG team for interplanetary magnetic field data. The work done at IFSI has been supported by the Agenzia Spaziale Italiana. A. Retinò is supported by the Swedish National Space Board.

Topical Editor T. Pulkkinen thanks R. L. Kessel and another referee for their help in evaluating this paper.

\section{References}

Avanov, L. A., Smirnov, V. N., Waite, J. H., Fuselier, S. A., and Vaisberg, O. L.: High-latitude magnetic reconnection in subAlfvénic flow: Interball tail observations on May 29, 1996, J. Geophys. Res., 29491-29 502, 2001.
Balogh, A., Carr, C. M., Acuña, M. H., Dunlop, M. W., Beek, T. J., Brown, P., Fornacon, K. H., Georgescu, E., Glassmeier, K. H., Harris, J., Musmann, G., Oddy, T., and Schwingenschuh, K.: The Cluster Magnetic Field Investigation: overview of in-flight performance and initial results , Ann. Geophys., 19, 1207-1217, 2001 ,

SRef-ID: 1432-0576/ag/2001-19-1207.

Bauer, T. M., Paschmann, G., Sckopke, N., Treumann, R. A., Baumjohann, W., and Phan, T. D.: Fluid and particle signatures of dayside reconnection, Ann. Geophys., 19, 1045-1063, 2001, SRef-ID: 1432-0576/ag/2001-19-1045.

Cowley, S. W. H.: The causes of convection in the Earth's magnetosphere - A review of developments during the IMS, Rev. Geophys. Space Phys., 20, 531-565, 1982.

Cowley, S. W. H.: Evidence for the occurrence and importance of reconnection between the Earths magnetic field and the interplanetary magnetic field, in: AGU Geophysical Monograph 30, edited by: Hones, E. W., 375-378, American Geophysical Union, 1984.

Cowley, S. W. H.: Theoretical perspectives of the magnetopasue: a Tutorial Review, in: AGU Geophysical Monograph 90, edited by: Song, P., Sonnerup, B., and Thomsen, M., 29-43, American Geophysical Union, 1995.

Crooker, N. U.: Dayside merging and cusp geometry, J. Geophys. Res., 84, 951-959, 1979.

Frey, H. U., Phan, T. D., Fuselier, S. A., and Mende, S. B.: Continuous magnetic reconnection at Earth's magnetopause, Nature, 426, 533-537, 2003.

Fuselier, S. A.: Kinetic Aspects of reconnection at the Magnetopause, in: AGU Geophysical Monograph 90, edited by: Song, P., Sonnerup, B., and Thomsen, M., 181-187, American Geophysical Union, 1995.

Fuselier, S. A., Petrinec, S. M., and Trattner, K. J.: Stability of the high-Latitude reconnection site for steady northward IMF, Geophys. Res. Lett., 27, 473, 2000.

Fuselier, S. A., Frey, H. U., Trattner, K. J., Mende, S. B., and Burch, J. L.: Cusp aurora dependence on interplanetary magnetic field B $_{z}$, J. Geophys. Res., 107, 6-1, 2002.

Gonzalez, W. D. and Mozer, F. S.: A quantitative model for the potential resulting from reconnection with an arbitrary interplanetary magnetic field, J. Geophys Res., 79, 4186-4194, 1974.

Gosling, J. T., Asbridge, J. R., Bame, S. J., Feldman, W. C., Paschmann, G., Sckopke, N., and Russell, C. T.: Evidence for quasi-stationary reconnection at the dayside magnetopause, J. Geophys. Res., 87, 2147-2158, 1982.

Gosling, J. T., Thomsen, M. F., Bame, S. J., Onsager, T. G., and Russell, C. T.: The electron edge of the low latitude boundary layer during accelerated flow events, Geophys. Res. Lett., 17, 1833-1836, 1990.

Gosling, J. T., Thomsen, M. F., Bame, S. J., Elphic, R. C., and Russell, C. T.: Observations of reconnection of interplanetary and lobe magnetic field lines at the high-latitude magnetopause, J. Geophys. Res., 96, 14 097-14 106, 1991.

Gosling, J. T., Thomsen, M. F., Le, G., and Russell, C. T.: Observations of magnetic reconnection at the lobe magnetopause, J. Geophys. Res., 101, 24 765-24 774, 1996.

Hudson, P. D.: Discontinuities in an anisotropic plasma and their identification in the solar wind, Planet. Space Sci., 18, 16111622, 1970.

Kessel, R. L., Chen, S.-H., Green, J. L., Fung, S. F., Boardsen, S. A., Tan, L. C., Eastman, T. E., Craven, J. D., and Frank, L. A.: Evidence of high-latitude reconnection during northward IMF: 
Hawkeye observations, Geophys. Res. Lett., 23, 583, 1996.

Luhmann, J. G., Walker, R. J., Russell, C. T., Crooker, N. U., Spreiter, J. R., and Stahara, S. S.: Patterns of potential magnetic field merging sites on the dayside magnetopause, J. Geophys. Res., 89, 1741-1744, 1984.

Marcucci, M. F., Bavassano Cattaneo, M. B., di Lellis, A. M., Cerulli Irelli, P., Kistler, L. M., Phan, T.-D., Haerendel, G., Klecker, B., Paschmann, G., Baumjohann, W., Möbius, E., Popecki, M. A., Sauvaud, J. A., Rème, H., Korth, A., et al.: Evidence for interplanetary magnetic field $\mathrm{B}_{y}$ controlled largescale reconnection at the dayside magnetopause, J. Geophys. Res., 27 497-27 508, 2000.

Nishida, A.: Can random reconnection on the magnetopause produce the low latitude boundary layer?, Geophys. Res. Lett., 16, 227-230, 1989.

Paschmann, G., Papamastorakis, I., Sckopke, N., Haerendel, G., Sonnerup, B. U. O., Bame, S. J., Asbridge, J. R., Gosling, J. T., Russel, C. T., and Elphic, R. C.: Plasma acceleration at the Earth's magnetopause - Evidence for reconnection, Nature, 282, 243-246, 1979.

Paschmann, G., Baumjohann, W., Sckopke, N., Papamastorakis, I., and Carlson, C. W.: The magnetopause for large magnetic shear - AMPTE/IRM observations, J. Geophys. Res., 91, 11099 $11115,1986$.

Phan, T. D., Kistler, L. M., Klecker, B., Haerendel, G., Paschmann, G., Sonnerup, B. U. Ö., Baumjohann, W., Bavassano-Cattaneo, M. B., Carlson, C. W., DiLellis, A. M., Fornacon, K.-H., Frank, L. A., Fujimoto, M., Georgescu, E., Kokubun, S., Moebius, E., Mukai, T., Øieroset, M., Paterson, W. R., and Reme, H.: Extended magnetic reconnection at the Earth's magnetopause from detection of bi-directional jets, Nature, 404, 848-850, 2000.

Phan, T. D., Sonnerup, B. U. Ö., and Lin, R. P.: Fluid and kinetics signatures of reconnection at the dawn tail magnetopause: Wind observations, J. Geophys. Res., 106, 25 489-25 502, 2001.

Phan, T. D., Frey, H. U., Frey, S., Peticolas, L., Fuselier, S., Carlson, C., Rème, H., Bosqued, J.-M., Balogh, A., Dunlop, M., Kistler, L., Mouikis, C., Dandouras, I., Sauvaud, J.-A., Mende, S., McFadden, J., Parks, G., Moebius, E., Klecker, B., Paschmann, G., Fujimoto, M., Petrinec, S., Marcucci, M. F., Korth, A., and Lundin, R.: Simultaneous Cluster and IMAGE observations of cusp reconnection and auroral proton spot for northward IMF, Geophys. Res. Lett., 30, 16-1, 2003.
Phan, T. D., Dunlop, M. W., Paschmann, G., Klecker, B., Bosqued, J. M., Reme, H., Balogh, A., Twitty, C., Mozer, F. S., Carlson, C. W., Mouikis, C., and Kistler, L. M.: Cluster observations of continuous reconnection at the magnetopause under steady interplanetary magnetic field conditions, Ann. Geophys., 22, 23552367, 2004,

SRef-ID: 1432-0576/ag/2004-22-2355.

Pinnock, M., Chisham, G., Coleman, I. J., Freeman, M. P., Hairston, M., and Villain, J.-P.: The location and rate of dayside reconnection during an interval of southward interplanetary magnetic field, Ann. Geophys., 21, 1467-1482, 2003,

SRef-ID: 1432-0576/ag/2003-21-1467.

Popescu, D., Sauvaud, J.-A., Fedorov, A., Budnik, E., Stenuit, H., and Moreau, T.: Evidence for a sunward flowing plasma layer adjacent to the tail high-latitude magnetopause during dawnward directed interplanetary magnetic field, J. Geophys. Res., 106, 29 479-29490, 2001.

Reme, H., Aoustin, C., Bosqued, J., et al.: First multispacecraft ion measurements in and near the Earths magnetosphere with the identical Cluster ion spectrometry (CIS) experiment, Ann. Geophys., 19, 1303-1354, 2001,

SRef-ID: 1432-0576/ag/2001-19-1303.

Russell, C. T. and Elphic, R. C.: Initial ISEE magnetometer results Magnetopause observations, Space Sci. Rev., 22, 681-715, 1978.

Safrankova, J., Nemecek, Z., Sibeck, D. G., Prech, L., Merka, J., and Santolik, O.: Two-point observation of high-latitude reconnection, Geophys. Res. Lett., 25, 4301-4304, 1998.

Sonnerup, B. U. Ö.: The Reconnecting Magnetosphere, in: ASSL Vol. 44, Magnetospheric Physics, 23-33, 1974.

Sonnerup, B. U. Ö., Paschmann, G., Papamastorakis, I., Sckopke, N., Haerendel, G., Bame, S. J., Asbridge, J. R., Gosling, J. T., and Russell, C. T.: Evidence for magnetic field reconnection at the earth's magnetopause, J. Geophys. Res., 86, 10 049-10 067 , 1981.

Trattner, K. J., Fuselier, S. A., and Petrinec, S. M.: Location of the reconnection line for northward interplanetary magnetic field, J. Geophys. Res., 109, 3219-3229, 2004. 